\title{
Transforming from Refugees to Entrepreneurs in Britain
}

\author{
Omar Sheikh Osman
}

\begin{abstract}
Recognizing the importance of refugees as potential entrepreneurs was the main reason that impelled the launch of small business start-up programmes. In Britain, The Entrepreneurial Refugee Network (TERN) was the principal institution concerned with refugees as potential entrepreneurs, whereas in Australia, the programme was run by the Ignite Small Business Start-Ups. The research question was based on investigating to what extent the British initiative programmes are immersed in supporting refugees' transformation into entrepreneurs, and to answer this question the researcher investigated how these programmes provide funds, training, and technical assistance. To place this in context, we compared the case of Britain with what has been achieved in Australia where the first worldwide experimental programme was applied. The aim of this comparison was to draw any lessons learned that could profitability be considered by the British programmes. Data was abstracted from the annual reports, and in addition, interviews conducted with the principals to ask about the size of loans granted, dates of loans, type of projects and the number of loans. It was noticeable that Ignite and TERN took a great interest in training, consulting, and advising their applicants. Both programmes were similar, even in number of beneficiaries. However, in Britain there was more interest in offering loans to potential entrepreneurs, especially the finance offered by the New Enterprise Allowance (NEA). Moreover, some businesses have been distinguished in their achievements, including such well-run successes as Dama Cheese and Fagee Fashion. On the other hand, the Start Up Loan Company offered financing compatible with the principles of Islamic Sharia which encourages more refugees to ask for finance.
\end{abstract}

Index Terms - Entrepreneurs, Refugees, Start Up Loan.

\section{INTRODUCTION}

It has been noted that there has been a vast amount of displacement of people over the last decade. UNHCR has reported that 68.5 million people had been forced to flee by December 2017, while 16.2 million fled in 2017; this means there were about 44,500 people daily who fled their home because of conflict or persecution [1].

Europe has been the main destination of refugees since the Second World War, and they have mostly fled from Syria, Iraq, Afghanistan, and Sudan. There were about 4 million refugees who registered in Europe between 2014 and 2017, and about 25\% of them had fled Syria [2].

The Organisation for Economic Co-operation and Development (OECD) reported that "warfare and instability in the Middle East and Africa" was the main reason to take an interest in immigration for humanitarian grounds, especially due to the disturbance took place in the MENA, which require reviewing the humanitarian programmes and

Published on December 17, 2020

Omar Sheikh Osman, Syrian Virtual University, Syria.

(corresponding e-mail: t_osheikhosman ${ }^{@}$ svuonline.org) procedures [3].

Syria was the principal source of recent refugees, where 6.3 million people fled their country. Accordingly, UK set up the Syrian Vulnerable Persons Resettlement Scheme (SVPRS) in 2015, which aimed to welcome 20 thousand Syrian refugees by mid-2020 [1].

Analysis of the position of refugees within the UK labor market by Block [4], [5] showed that refugees have a low level of economic participation, work unsocial, and take low pay, while those with skills often do not practice their professions. The main factors with an effect on refugee employment were English language proficiency, level of education, length of residence, migrant aspirations, and participation in training.

Collins [6] reported difficulties encountered by refugees when they take part in entrepreneurship: shortage of capital to set up a new business; lack of credit and assets; lack of education or educational qualification unacceptable in the workplace; poor social connections; difficulties in finding sources of support; lack of knowledge of markets and of regulations and rules concerning settling and starting new businesses. These are the greatest barriers that hinder new refugees looking to transform themselves into entrepreneurs.

Introducing entrepreneurship instead of employment produces the best possible path toward economic integration, with significant potential benefits to both the entrepreneurs and the host country. There are many examples of entrepreneurs who succeeded transforming themselves from refugees: Andrew Grove who escaped Hungary "when he was 20 years old" after World War II and founded Intel as a refugee in the US; Lakshmishankar and Shanta Pathak who escaped Kenya in the 1950s to set up the food brand Patak; Sergey Brin, the cofounder of Google, whose family left the USSR with him to settle in the US; Dame Stephanie Shirley who fled Germany on the outbreak of World War II, arriving in the UK before becoming a pioneer in technology; and Michael Marks, the co-founder of retailer Marks \& Spencer, who emigrated to England in 1882 [7].

Recognising the importance of refugees as potential entrepreneurs was the main reason that impelled the Ignite Small Business Start-Ups programme to launch in Australia and to set up a three-year fund programme to help refugees looking to transform into entrepreneurs. It was recognised that refugees have previous experience and though they need support to start their business in a new environment they are willing to restart their own business life. Setting up a new business is accomplished to enable the applicants to run a business they already are expert in by supporting them with supervision, helping them with interpreting, assisting them to strengthen networks and to access funding support; all these kinds of support are free of charge [8]. On the other hand, Thrive Refugee Enterprise, also based in Australia, 
has a primary role in providing microfinance to help refugees and to support them in setting up their own businesses. Thrive recognises that there is an opportunity to help refugees who are looking to start up their own business by supporting them to achieve a success which is beneficial to them and the economy [9].

In Britain, there were about 880 refugees who were beneficiaries of the New Enterprise Allowance (NEA) programme from 2011 to 2017, and about 350 of them set up their own successful businesses [7]. NEA, which is supported by the Department for Work and Pensions (DWP), provides support to unemployed persons who wish to be self-employed. The Start Up Loan Company with the support of the DWP looks after participants in the NEA programme who are entitled to finance to set up their own business where they have been registered in the NEA programme for the previous 10 months. The applicants are eligible to ask for a set-up loan amounting to between $£ 500$ and $£ 25,000$ where they benefit from any NEA business plan approval [10]. The Entrepreneurial Refugee Network (TERN) is a project based in Britain to maintain and help refugees; however, they support the applicants who either are running their business and need help to expand or have business ideas and need guidance [11].

The problem of discounting refugees as potential entrepreneurs is a global phenomenon. However, refugees have common characteristics wherever they are, whether in Britain, Australia, or other parts of the world. Given Britain has had a wealth of refugees, many of these potentially merit support and help in starting up their own business.

The question raised in this research is to what extent these British initiative programmes are immersed in supporting refugees' transformation into entrepreneurs, and to answer this question we are looking at whether these programmes provide funds, training, or any other technical assistance such as consulting. To place this in context, the researcher will compare the case of Britain with what has been achieved in Australia where the first worldwide experimental programme to support refugees' transformation into entrepreneurs was applied. The aim of this comparison is to draw some of lessons learned that could profitably be considered by the British programmes.

Data sources are the annual reports of these institutions and interviews conducted with the principals responsible for achieving these programmes to gather data regarding the provision of loans to applicable refugees to start up their own businesses. Among other data, data about the size of loans granted and any other available data concerning dates of loans, types of project and the number of loans was used to answer the research question related to their role in supporting refugees' transformation into entrepreneurs and what kind of support they provide.

\section{PROGRAMMES}

Comparisons between the initiative programmes offered in Australia by Ignite Small Business Start-ups and what is offered in Britain by the Start Up Loan Company and the Entrepreneurial Refugee Network (TERN) - how they help refugees to transform into entrepreneurs, what they provide them regarding funds ("size, dates and number of loans"), types of project, training, and technical assistance such as consulting and advising - are analyzed here.

\section{A. Ignite Small Business Start-ups}

The Ignite programme accepted 240 clients, most of them from the Middle East. They held 30 different nationalities with 27 different native languages. Eighty percent of them (186) were males and twenty percent (54) were females.

Roughly, 61 of clients -45 males and 16 females - held a higher education certificate and 69 of them -61 males and 8 females - attended secondary school, whereas only 4 clients studied at primary school and 3 declared that they had had no formal education.

There were 61 projects established successfully under the programme, and 54 of them passed the assessment criteria. The diversity of the enterprises they ran ranging across 10 different businesses classes was remarkable, and most of their interest was in retail, cafes, and restaurants. Table 1 shows the classes of the businesses set up:

TABLE 1: ENTERPRISES OPERATED BY ENTREPRENEURS AT IGNI
\begin{tabular}{cc} 
CLASS \\
\hline Business Class & Started-up \\
\hline Manufacturing & 1 \\
Electricity, Gas and Water & 2 \\
Supply & 6 \\
Construction & 2 \\
Wholesale Trade & 15 \\
Retail Trade & 5 \\
Accommodation, Cafes and & 3 \\
Restaurants & 3 \\
Transport and Storage & 12 \\
Property and Business Services & 5 \\
Cultural and Recreational & \\
Services & \\
Personal and Other Services &
\end{tabular}

Most of the clients had experience in their home countries in fields such as electrical engineering, filming, fencing, floor sanding and polishing, water treatment systems, photography, and video, and one of them was carrying out two different types of work, IT, and photography, while another was running both his family's hairdressing shop and a cafe. Some clients, on the other hand, set up their business without having any previous experience.

The programme interviewed 31 men and 8 women to find out about their previous experience: $32 \%$ of men and $50 \%$ of women recommenced the type of work they had expertise in; $26 \%$ of men and $12 \%$ of women set up in a new field of business; and a similar percentage of men $(42 \%)$ and women $(38 \%)$ set up a new business without having any previous experience. Most small enterprises need some years before gaining profit; 13 male $(42 \%)$ and 5 female (63\%) entrepreneurs had achieved profitable projects under Ignite.

Taking into consideration the future of their own work, 24 of 31 males and 6 of 8 females looked to grow their enterprise within 5 years, and a similar number of clients were expecting to start hiring new staff to expand their business in the same period. As for the time required to establish a business, 33 customers $(92 \%)$ had established the business within 10 months of programme approval. 28 (78\%) had started their business by 4 months, 13 of whom $(36 \%)$ needed less than two months, while other $5(14 \%)$ needed 5 to 10 months to start up, and the remaining $3(8 \%)$ needed up to 26 months to set up. 
The programme supports the economy with savings, payments, tax return, and innovative new projects. As these businesses develop, new employees are hired; 20 employees had already been hired, and 25 entrepreneurs intended to hire new staff.

Roughly $50 \%$ of the businesses invested their savings to start up their projects, almost $25 \%$ were funded by relatives and/or friends and $10 \%$ of males spent both savings and funding from others to set up their projects. One woman and a few men benefited from micro-finance arranged by the programme, whereas one applicant was funded by a loan from a financial institution, and another man was not in need of much funding. Table 2 shows where the customers obtained the funds to set up the businesses:

TABLE 2: SOURCES OF START-UP FUNDS BY ENTREPRENEURS AT IGNITE

\begin{tabular}{cc}
\hline Source & Number \\
\hline Savings & 28 \\
Loans from relatives/friends & 15 \\
Savings and loans from others & 5 \\
Microfinance arranged by the programme & 4 \\
Loan from a financial institution & 1 \\
No capital required & 1 \\
\hline
\end{tabular}

These figures show us how the programme ran successfully in providing help to refugees in setting up their own businesses through the first 3 years of their arrival. The establishment of 61 new businesses was beyond expectations in overcoming the difficulties of financial, social, human and language barriers.

\section{B. Start Up Loan Company}

The Start Up Loan Company is a British Business Bank subsidiary set up in 2012 to help and support funding and mentoring start-up and fledgling businesses to set up or to expand. They provide the Government's Start Up Loans Programme and work with a national network of Delivery Partners that spans England, Wales, Scotland, and Northern Ireland. The Delivery Partners support customers in setting up business plans and estimates of the business's cashflow and assessing the final applications and offering mentoring to the successful customers. They also operate with two Finance Partners, Street UK Limited and the Enterprise Loan Fund Ltd. The Finance Partners set up the funding agreements with the successful applicants and follow up the administration and the repayments of loans. The Start Up Loans Company supervises its Delivery Partners and Finance Partners to ensure consistent support for customers and ensure that good financing decisions are taken.

Start Up Loans do not require guarantees, as they are supported by the government and they are offered to individuals willing to set up their own business. Applicants receive one year's mentoring for free and assistant to succeed in their projects. The maximum amount of loan offered is $£ 25,000$ to individuals and $£ 100,000$ to businesses. It should be noted that the average amount of loan granted is $£ 7,200$ with an annual interest rate $6 \%$ and maturity of 1 to 5 years.

The company takes Islamic principles in finance into consideration, and they offer funding in compliance with Sharia. This finance does not attract any interest on the fund supplied but relies on advance agreement to share the profits of the business. The profit is shared and based on a $6.19 \%$ rate of return on investment and paid monthly. After the investor has applied for the project, Financing Sharia Enterprise assesses the eligibility and estimates the due payment based on the investment amount. If the application is approved and agreed, the investment is regularly reviewed and assessed. This programme is available to all customers whatever their religious faith, and they receive 12 months support, guidance, and advice while their business progresses.

According to the regulations in Britain, it is not mandatory for loan applicants to declare their visa type. However, from 16th May 2017 loan applicants have been able to self-declare this, and consequently there is only data where it has been provided by the applicant, which accounts for a relatively small portion of the Start Up Loans Company's loan book. Table 3 shows the amount of Start Up Loan Company loans issued to applicants who have a visa type of Asylum:

TABLE 3: LOANS GRANTED BY START UP LOAN COMPANY

\begin{tabular}{ccc} 
Drawn Down Date & Loan Amount $(£)$ & Industry Sector \\
$08 / 11 / 2018$ & 15,000 & Corner shops \\
$14 / 01 / 2019$ & 1,500 & Online marketing \\
$31 / 05 / 2019$ & 5,000 & Cafes, snack bars and tea \\
& & rooms \\
$14 / 06 / 2019$ & 15,000 & Cleaning services - \\
& & domestic \\
\hline
\end{tabular}

One of the successful projects was a loan granted to Razan Al Sous who had fled Syria for the UK with her family due to the outbreak of war; despite holding a higher educational certificate, she struggled to find employment. She therefore thought about establishing a new project to produce cheese; and after researching the market and the competitors, and carrying out a feasibility study, she set up her business with the support of a $£ 2,500$ Start Up Loan, establishing Yorkshire Dama Cheese to produce Halloumi cheese, a product that is widely regarded as having originated in the Middle East. This required producing the cheese and distributing the product in the market with her limited funds. Her husband, an electrical engineer, supported her in adapting the manufacturing tools to produce the cheese, which she made using locally sourced milk. She started her small factory in a property owned by her brother-in-law, helping her cut the costs down. Only 4 months after the business was set up, she won the World Cheese Award Bronze Medal, a competition between 2,750 producers. She was chosen as an ambassador for the International Women's Day by the prime minster, David Cameron, and won the Deliciously Yorkshire Award for Best Cheese and Best New Business, also appearing with the TV chef James Martin on his BBC1 programme. She also won the World Cheese Award Gold Prize, was shortlisted for Best Cheese at the Yorkshire Deliciously Yorkshire Awards and for Best New Business at the British Muslim Awards. Encouraged by these successes, she came up with the idea of setting up a new shop named the Road to Damascus. She was honoured by HRH The Princess Royal opening her new factory in Sowerby Bridge on 25th January 2017, when she introduced her new smoked halloumi cheese at the opening. She also plans to open a deli shop at the factory where visitors can taste her products on spot, and to 
re-brand the product with a new name, 'Yorkshire Squeaky.'

\section{The Entrepreneurial Refugee Network (TERN)}

TERN recognises refugees who face difficulties in setting up their own businesses. They consider refugee entrepreneurship and business partnerships as a win-win, a means of increasing harmony and economic integration. They try to leverage the expertise and goodwill of experienced entrepreneurs and industry experts in Britain to provide a healthy, growth-oriented entrepreneurial ecosystem for refugee entrepreneurs, using a 12-week incubation programme for refugee entrepreneurs, including weekly mentorship, training events, tailored expert advice and access to finance.

At first contact, TERN assesses applicants' needs and entrepreneurial progress. They then channel them either to start at one of the 3 stages or to refer them to appropriate partners in the employability space. Stage 1, Pre-Incubator, is for refugees who are unsure about the details of their businesses; they are offered ideation workshops and assistance with initial market research. Stage 2, Start-up Incubator, concerns refugees who are in the process of starting their own business; many require a start-up loan. Stage 3, Growth Accelerator, relates to refugees who want to grow their existing business; most of them require investment rather than loans. TERN started a Pre-Incubator pathway in cooperation with Ice Cream superstars Ben \& Jerry's; the company works with the applicants for a combination of income generating activity and entrepreneurship training to help them set out on a path towards financial and professional independence.

TERN provides tailored and holistic business support for refugee entrepreneurs, and plan to enable 1000 refugees to launch businesses by 2025. Since its foundation in 2016, over 160 refugee entrepreneurs have received business support from TERN, who as a result had helped launch over 35 new businesses in the UK to date. Their Incubator model works with three different specialist volunteer roles to support participants. TERN assigns every refugee entrepreneur a personal mentor, and together they hold weekly 60-90-minute meetings. In the meeting, the mentor provides feedback, addresses challenges and helps the mentee build, refine, and validate their proposition and business plan. TERN maintains a pool of expert advisors who give participants tailored advice sessions (online or face to face) at the point of need. TERN experts cover legal matters, accounting, marketing, social media, pitch readiness and cash flow. TERN matches refugee entrepreneurs with entrepreneurs in their local area and chosen business domain; these 'business buddies' facilitate access to networks and routes to market and provide refugee entrepreneurs a low-risk environment to test and validate their Minimum Viable Product. Some buddies become more actively involved as business partners of the refugee business.

One refugee who received the supported of TERN is Faith Gakanye, a Zimbabwean social entrepreneur based in Nottingham. She focuses on ethical clothing and décor aimed to brighten up the skies of the UK with African colours. Her business was registered as Fagee Fashion, and the loan reviewed during mentoring was $£ 28,000$. Her requirements were structured mentorship, access to improved sewing machines and storage space, loan capital for sewing machines, and advice on social enterprise propositions and fair-trade standards. In another case, Ahmad, a Syrian catering entrepreneur based in London aimed to start a restaurant following the success of an earlier business and social enterprise, the Aleppo Supper Club. His idea was to open a big restaurant to show people Syrian art and culinary culture and to help other refugees to do similar projects. His requirements were business strategy and awareness of the lean start-up model, business networking in the social café and dining experience domains, business registration, marketing, and social media strategy, and development of the brand.

\section{DISCUSSION}

The initiative programmes offered both in Australia and Britain were established during the last decade, where Ignite programme was launched in 2013, the Start Up Loan Company was established in 2012, and The Entrepreneurial Refugee Network (TERN) was founded in 2016. These closely grouped dates are good enough to allow us to evaluate their whole achievements objectively.

Discussing the services, they have offered, it is clearly noticeable that Ignite has helped in introducing its clients to micro-finance institutions and guiding them throughout the project' stages, creating the brand name, setting up a website, connecting with suppliers, finding out distribution channels, setting pricing and marketing campaigns, and creating business plans. By contrast, The Start Up Loan Company was concerned more with finance and helped customers through cost-free mentoring and access to business services at reduced cost to ensure their success, while TERN offered 2-week incubation programme for refugee entrepreneurs, including weekly mentorship, training, tailored expert advice and access to finance, supporting the applicants with legal matters, accounting, marketing, social media, pitch readiness, and cash flow.

Ignite and TERN took a great interest in training, consulting, and advising their applicants. The Ignite programme was based on a 4-stage process, starting with gauging the refugees' passion for their business and assessing their entrepreneurial potential, followed by assistance and professional advice; then finalising basic trading requirements such as getting a brand name, a business website, marketing materials, and setting up bills of purchase and sale; and finally facilitating fund inflow to start up a business and buy required materials and assisting in connecting them with partners. On the other hand, TERN was based on a 3-stage process, starting with offering ideation workshops to refugees who are unsure about the details of their proposed business and assisting them with initial market research; then taking care of refugees who are in the process of setting up their business and mainly require a start-up loan; and finally dealing with refugees who want to grow their existing business, most of whom require investment rather than loans.

Comparing what has been achieved by these companies, it has been shown that there were 61 new businesses set up within 3 years by Ignite, while over than 160 refugee 
entrepreneurs have received business support from TERN which as a result helped in launching over 35 new businesses till 2019, and which planned to enable 1000 refugees to launch businesses by 2025. Most start-ups facilitated either by Ignite or TERN operated in manufacturing, electricity, gas and water supply, construction, wholesale trade, retail trade, accommodation, cafés and restaurants, transport and storage, property and business services, cultural and recreational services, and personal and other services.

Moving our attention to the sources of capital inflow, savings and funding from relatives and friends have been the primary source of entrepreneurs' capital; only a few businesses required microfinance from either Ignite or TERN. On the other hand, there were about 359 refugees who set up businesses in Britain after benefiting from the New Enterprise Allowance (NEA). The Start-Up Loan Company was offering up to $£ 25,000$ to each applicant; the loan repayment term is between one to five years, and they have even developed a Sharia compliant investment product. Following British regulations of the 16th May 2017, loan applicants have been able to self-declare their visa type; this has revealed that a total loan amount of $£ 36,500$ was granted to refugees in the first half of 2019. Among the industry sectors financed were corner shops, online marketing, cafés, snack bars and tea rooms, and cleaning services.

Britain has been distinguished by successful projects established by refugees, such as Yorkshire Dama Cheese financed with just $£ 2,500$ by NEA, and Fagee Fashion with $£ 28,000$ by TERN.

We conclude that in Britain there is a great interest in offering loans to potential entrepreneurs, especially the finance offered by NEA. Moreover, there is diversity among the types of business set up, and some have been distinguished in their achievements, including such well-run successes as Dama Cheese and Fagee Fashion.

The characteristics of some refugees such as Islamic ethics have been considered by the Start Up Loan Company which offered financing compatible with the principles of Islamic Sharia by sharing the profit and loss of projects instead of requiring interest on loans; this could encourage more refugees of Islamic religion to ask for finance and start up their own businesses.

The variety of businesses started up benefits both the refugees and the economy of the host country, where refugees can start up their own business and contribute to production in the economy, resulting in benefit to the economy through taxes raised and offering opportunity of work to unemployed refugees.

Lastly, TERN has given refugees a great training opportunity to those who are in the Pre-Incubator pathway in cooperation with Ben \& Jerry's that helps them towards financial and professional independence.

\section{REFERENCES}

[1] United Nations High Commissioner for Refugees (UNHCR). Global Trends 2017, Geneva, 2018.

[2] OECD, SOPEMI: International Migration Outlook, OECD Publishing, Paris, 2018.

[3] OECD, SOPEMI: International Migration Outlook, OECD Publishing, Paris, 2015.
[4] Block, Alice. Refugee Employment in the UK, Asylum and Migration working paper 2, Institute of Public Policy Research, 2004.

[5] Block, Alice. Refugee Employment in the UK, Institute of Public Policy Research, London, 2004.

[6] Collins, Jock. From Refugee to Entrepreneur in Sydney in Less Than Three Years, Final Evaluation Report on the SSI IGNITE, Small Business Start-ups Program, UTS Business School, Sydney, 2017.

[7] CFE. How Entrepreneurship is transforming the Lives of Resettled Refugees, Centre of Entrepreneurship, 2018.

[8] www.ssi.org.au/services/ignite.

[9] thriverefugeeenterprise.org.au.

[10] www.startuploans.co.uk

[11] www.wearetern.org.

[12] Atkinson, Adele. Migrants and Financial Services: A Review of the Situation in the United Kingdom, Personal Finance Research Centre, University of Bristol, 2006.

[13] Berns, Judit. Exploring Refugee Entrepreneurial Intent in the Netherlands, Master Thesis, International Management, Radboud University Nijmegen, School of Management, 2017.

[14] Betts, Alexander. Olivier, Sterck. Remco, Geervliet and Claire, MacPherson. Talent displaced: The Economic lives of Syrian Refugees in Europe, Refugee Studies Centre, University of Oxford and Deloitte Northwest Europe, UK, 2017.

[15] Dagnelie, Olivier. Mayda, Anna Maria. And Maystadt, Jean-François. The Labour Market Integration of Refugees to the United States: Do Entrepreneurs in the Network Help? IZA - Institute of Labour Economics, 2018.

[16] Davison, Hilary. Fitzgerald, Ian and Hudson, Lucinda. Refugee Business Start-ups in the North East of England: An Impossible Dream. Northumbria University, 2013.

[17] Fong, Rowena. Bridget Busch, Noel. Armour, Marilyn. Cook Heffron, Laurie and Chanmugam, Amy. Pathways to SelfSufficiency: Successful Entrepreneurship for Refugees, Journal of Ethnic and Cultural Diversity in Social Work, 2007.

[18] Jones, T. Ram, M., Li, Y. Edwards, P. and Villares, M., SuperDiverse Britain and New Migrant Enterprises, Iris Working Paper Series, No 8, Birmingham, Institute for Research into Superdiversity, 2015.

[19] Kenneth, Clark and Drinkwater, Stephen. Pushed Out or Pulled In? Self-Employment Among Ethnic Minorities in England and Wales, Labor Economics, Volume 7, Issue 5, September 2000, 603-628.

[20] Lyon, Fergus. Sepulveda, Leanardo and Syrett, Stephen. Enterprising Refugees: Contributions and Challenges in Deprived Urban Areas, Centre for Enterprise, and Economic Development Research (CEEDR), Middlesex University Business School, UK, 2007.

[21] OECD. How are Refugees Faring on the Labour Market in Europe? A first Evaluation based on the 2014 EU Labour Force Survey Ad Hoc Module, Working Paper 1/2016.

[22] Rashid, Lubna, Call Me a Business Owner, Not a Refugee, Challenges of and Perspectives on Newcomer Entrepreneurship, World Refugee Council Research Paper No. 7, 2018.

[23] Refai, Deema, Haloub, Radi and Lever, John. Contextualizing Entrepreneurial Identity amongst Syrian Refugees in Jordan: The Emergence of a Destabilized Habitus. Department of Management, University of Huddersfield, Huddersfield, UK, 2018.

[24] Refugee Studies Centre. Resettled Syrian Refugees in Oxford, Oxford Department of International Development, University of Oxford, 2018. 